\title{
Driving Pockels Cells Using Avalanche Transistor Pulsers
}

\author{
E. S. Fulkerson \\ D. C. Norman \\ R. Booth
}

This paper was prepared for and presented at the 11th IEEE International Pulse Power Conference

Baltimore, Maryland

June 29-July 2, 1997

May 28, 1997

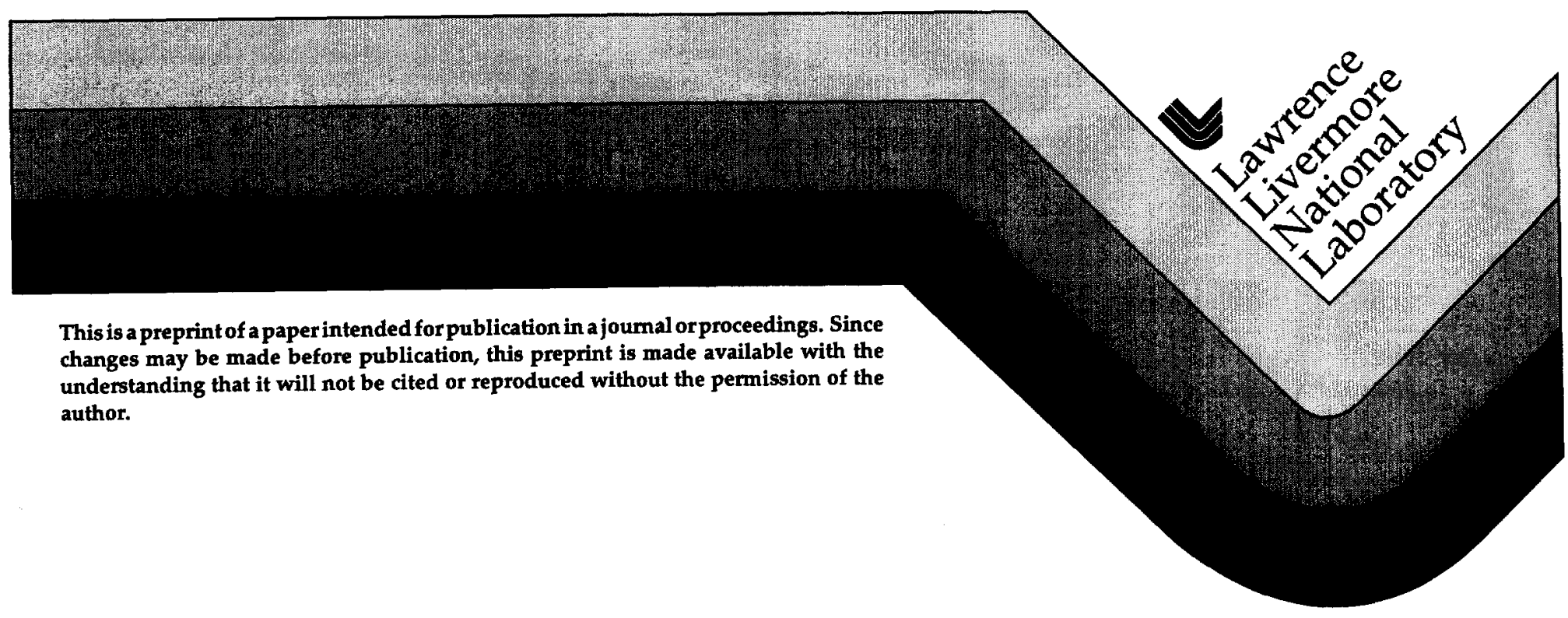




\section{DISCLAIMER}

This document was prepared as an account of work sponsored by an agency of the United States Government. Neither the United States Government nor the University of California nor any of their employees, makes any warranty, express or implied, or assumes any legal liability or responsibility for the accuracy, completeness, or usefulness of any information, apparatus, product, or process

disclosed, or represents that its use would not infringe privately owned rights. Reference herein to any specific commercial product, process, or service by trade name, trademark, manufacturer, or otherwise, does not necessarily constitute or imply its endorsement, recommendation, or favoring by the United States Government or the University of California. The views and opinions of authors expressed herein do not necessarily state or reflect those of the United States Government or the University of California, and shall not be used for advertising or product endorsement purposes. 


\title{
DRIVING POCKELS CELLS USING AVALANCHE TRANSISTOR PULSERS ${ }^{1}$
}

\author{
E. Stephen Fulkerson \\ Lawrence Livermore National Laboratory \\ PO Box 808 L-054 \\ Livermore, CA 94551-0808 \\ Douglas C. Norman \\ Lawrence Livermore National Laboratory \\ PO Box 808 L-044 \\ Livermore, CA 94551-0808 \\ Rex Booth \\ E2 Consulting Engineering Incorporated \\ PO Box 808 L-043 \\ Livermore, CA 94551-0808
}

\section{Introduction}

The purpose of this paper is to describe the current state of avalanche transistor based Pockels cell driver development at LLNL and to provide the reader with a set of useful design guidelines. A general description of the units is followed by a short section on the circuit design of avalanche transistor pulsers. A more detailed design guide is given in reference 1 . Techniques for delivering either $1 / 4$ or $1 / 2$ wave voltages to a Pockels cell are covered. Recently these units have been modified for use at repetition rates up to $10 \mathrm{kHz}$. Operating at high repetition rates presents problems for both the driver and the Pockels Cell. Design solutions for the pulser are presented as well as a discussion of Pockels cell acoustic resonance.

\section{General Description and Specifications}

The authors have developed several avalanche transistor based pulsers for driving industry standard $10 \mathrm{~mm}$ aperture Pockels cell electro-optic light modulators. Units that have been built and tested to date are $1 / 4$-Wave $1060 \mathrm{~nm}$ low repetition rate $(\leq 1 \mathrm{kHz})$ devices, $800 \mathrm{~nm} 1 / 4$-wave $10 \mathrm{kHz}$ systems, and 1060nm 1/2-wave drivers for both low PRF $(<500 \mathrm{~Hz})$ and $1 \mathrm{kHz}$ operation. These units are tightly integrated with the optical cell, avalanche pulser, and (for low PRF applications) the high voltage power supply mounted in a single compact (2"x3"x6") EMI shielded enclosure. Units with an internal high voltage supply require only a single $+24 \mathrm{Vdc}$ power supply and a TTL level trigger. Operation at higher repetition rates requires an external high voltage supply and $+12 \mathrm{~V}$ fan power as well as the trigger signal. Optical switching speeds in the range of $850 \mathrm{ps}$ to $1.3 \mathrm{~ns}$ have been measured at both $1 / 4$-Wave $(4.5 \mathrm{kV})$ and $1 / 2$-Wave $(9 \mathrm{kV})$ output voltages. Trigger delay jitter is $<200$ ps one sigma. Prototype $1 / 4$-Wave units have been in service for over a year with no failures.

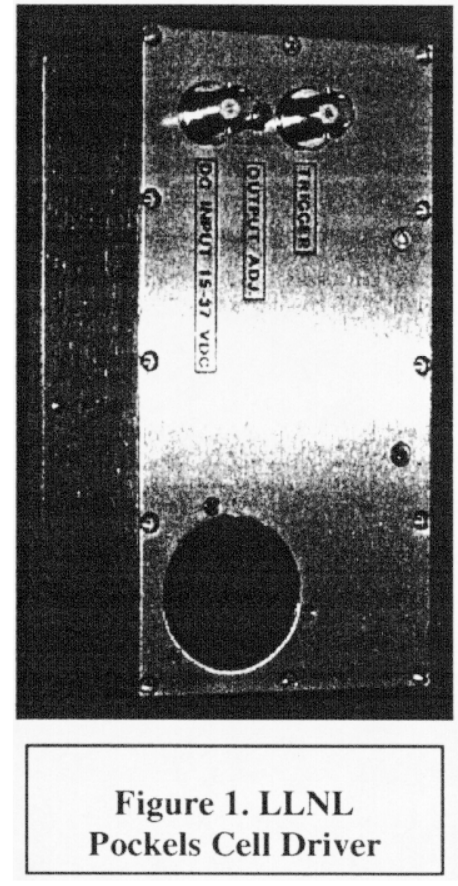

\footnotetext{
${ }^{1}$ Work performed under the auspices of the U.S. Department of Energy by the Lawrence Livermore National Laboratory under Contract W-7405-ENG-48.
} 


\section{Basic Avalanche Pulser Design}

Figure 2 shows a simplified quarter wave driver circuit. For design purposes the Pockels cell is treated as a simple capacitive load $(\approx 6 \mathrm{pF}$ for the $10 \mathrm{~mm}$ cells used). Only three stages are shown, in actuality 12 to 16 stages would be required depending on the output voltage required. The basic circuit is a string of avalanche transistors and capacitors from the high voltage supply to ground. The inductance of the transistors $(\approx 2 \mathrm{nH})$ along with the capacitors can be thought of as a lumped element LC transmission line. In order to keep parasitic inductance to a minimum, lands directly on the surface of the printed circuit board form the capacitors. The impedance from stage to stage tapers smoothly from $50 \Omega$ at the output to about $3 \Omega$ at the low voltage end. The string is terminated (R1) at the trigger end to prevent reflections that may damage the transistors.

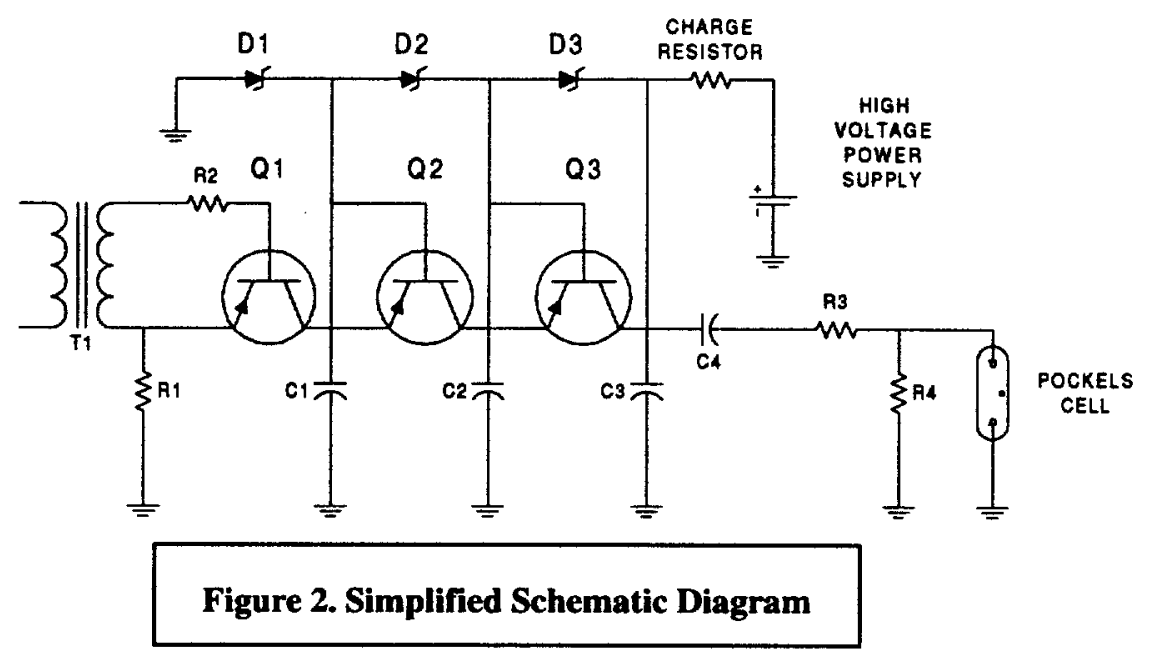

The transistors are Zetex Inc. FMMT-417 surface mount (SOT-23) NPN silicon planar avalanche units with a guaranteed minimum Collector-Base breakdown voltage $\left(\mathrm{V}_{\mathrm{cbo}}\right)$ of $320 \mathrm{~V}$. The zener diode at each stage limits the $\mathrm{DC}$ voltage across the transistors to a value slightly below the transistor's avalanche voltage. Keeping the transistors out of this breakdown region produces more consistent operation from stage to stage and results in a circuit that is more noise immune.

Operation is simple; the bottom (lowest voltage) stage is triggered via pulse transformer (T1) this places the collector of Q1 near ground resulting in about $600 \mathrm{~V}$ collector to emitter across Q2. The second stage transistor suffers an avalanche breakdown due to this over voltage. Each succeeding stage "sees" an even greater over voltage and we get a "crack-the-whip" effect that produces faster rise times and shorted stageto-stage delays as the pulse nears the output. There is no voltage applied to the output until the final stage (Q3) switches, thus in the limit, the electrical rise time is set by how fast the last transistor turns on. A typical output voltage waveform is shown in Figure 3. Rise times under 100ps have been obtained. The pulse width is about one to two microseconds and is determined by the recovery time of the transistors. The trailing edge fall time is long and is set by the charging resistor and the capacitance of the string. Because the Pockels cell presents a capacitive load the electrical rise can not be measured directly due to the bandwidth limits of high impedance oscilloscope probes. Electrical performance must be inferred from the optical measurement. However for the size and type (10mm KD*P) of Pockels cell used the optical rise time is limited to about $1 \mathrm{~ns}$. This is due to transit time effects in a medium with a dielectric constant of 55. (See Figure 3. For a typical output pulse) 
Coupling capacitor $\mathrm{C} 4$ provides a block so that no DC voltage is applied to the Pockels cell. Depending on the crystal used some Pockels cell will darken or "fog" with long term DC voltage exposure. R3 provides impedance matching to the string during the pulse rise time again preventing reflections than could damage the transistors. Resistor R4 has two functions; provide a $\mathrm{DC}$ charging path for the coupling capacitor $\mathrm{C} 3$ and to discharge the capacitance of the Pockels cell.

For the $10 \mathrm{~mm}$ aperture cells employed in these designs the half wave voltage at a wavelength of $1060 \mathrm{~nm}$ is approximately

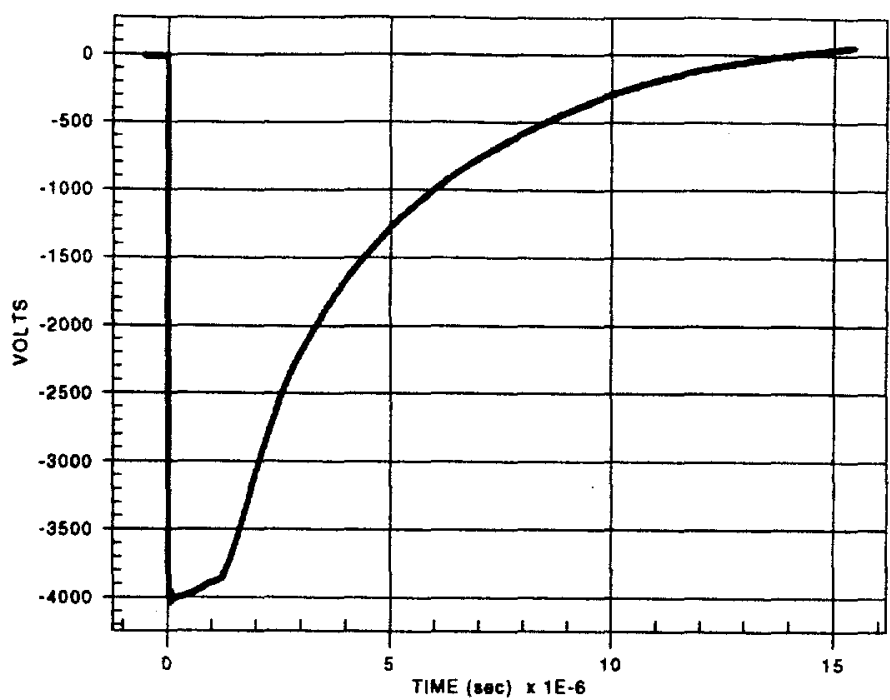
$9 \mathrm{kV}$. A single string of about 32 stages with a $10 \mathrm{kVdc}$ power supply could be designed to achieve this voltage. There are several problems with this approach; 1) The circuit would be physically long resulting in a much larger enclosure. 2) The capacitance per stage at the load end of the string would be vanishingly small resulting in printed circuit lands too small to mount components to. 3) Corona and ozone generation would become a problem due to the high supply voltage. Figure 4 below shows a system that addresses these problems. What is shown are the final stages of two $1 / 4$-wave units used in a push-pull configuration. The transistors and diodes in the circuit on the right have been reversed along with the polarity of their high voltage supply. The pulser on the left produces a negative output pulse at the quarter wave voltage of the cell, the circuit to the right produces a positive output. When the system is triggered the total voltage across the cell will be at the half-wave potential. The two physically identical strings can be built side by side on the same printed circuit board. The maximum power supply potential is only $5 \mathrm{kV}$.

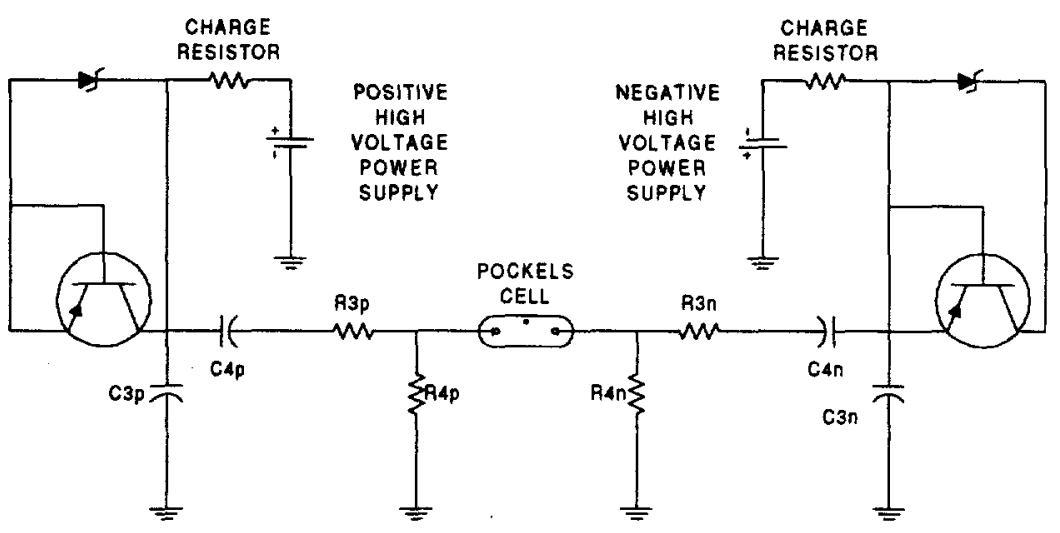

Figure 4. Push-Pull 1/2-Wave Driver

There is some cost in complexity as that now a trigger circuit must be added that triggers both strings and that can slightly vary the trigger time between the two halves of the circuit. If one string fires significantly before the other, the late side will be triggered by the pulse arriving through the Pockels cell from the first. The colliding wave fronts produce reflections that can damage transistors in the late string. This has not 
proven to be a significant problem in practice, the timing is set during initial check-out and results in a reliable half-wave driver.

\section{High Repetition Rate Considerations}

To assure proper operation at high repetition rates there are three conditions that must be meet; 1) The output coupling capacitor must be fully recharged before the next pulse. 2) The voltage across each stage in at least the lower half of the string (the portion closest to the trigger) must be close to the avalanche voltage of the transistors. 3) The voltage drop across the zener diodes must not exceed the avalanche voltage of the transistors.

During each shot the voltage stored in C4 (See Figure 2 again) is applied to the Pockels cell for the duration of the output pulse. The value of $\mathrm{C} 4$ determines both the final voltage across the cell and the output voltage droop during each pulse. $\mathrm{C} 4$ and the Pockels cell form a capacitive voltage divider. In these units we wanted $95 \%$ of the charge voltage to be applied to the cell so that $\mathrm{C} 4$ must be at least 20 times the capacitance of the cell $(\geq 120 \mathrm{pF}$ for a $6 \mathrm{pF}$ cell). The coupling capacitor is partially discharged via R4each pulse, this is seen as voltage droop at the cell. A value for R4 is chosen that will allow C4 to recharge during the inter-pulse period but will not cause excessive droop during the pulse. The pulse width is fixed by the recovery time of the avalanche transistors and is between one and $2 \mu \mathrm{s}$. The inter-pulse period is much longer than the output pulse so that selecting a value for R4 is driven almost exclusively by droop considerations with a check to ensure a value compatible with charging the coupling capacitor.

As noted earlier, there is "crack-the-whip" effect as the pulse proceeds down the chain. We have found that if at least the lower half of the string is fully biased, the system will produce constant output pulses. In order to operate at $10 \mathrm{kHz}$ we only have $100 \mu \mathrm{s}$ to recharge the string before the next pulse. This is not as easy as it seems as the zener diodes in the charge path complicate the matter. Still referring to Figure 2, let us assume the pulser has just fired and capacitors $\mathrm{C} 1, \mathrm{C} 2$, and $\mathrm{C} 3$ are fully discharged. The power supply will attempt to charge each of the capacitors through the charge resistor and the string of zener diodes. At first all three zeners are off and only C3 will begin to charge. When the voltage across $\mathrm{C} 3$ reaches the zener voltage of the diode $\mathrm{D} 3$, the zener will turn on and now both $\mathrm{C} 2$ and $\mathrm{C} 3$ will begin to charge.

Figure 5 below is the output of a SPICE simulation for this circuit. Note that the rate at which $\mathrm{C} 3$ is charging (the upper trace) decreases as the power supply tries to charge two capacitors through the same charge resistor. Observe that $\mathrm{Cl}$ does not begin to charge until both D2 and D3 turn on, for long strings this delay in charging can be a serious problem. The solution is to introduce several charging resistors along the string. A "ballpark" figure for the value of the charge resistor can be obtained by lumping all the capacitance values between it and the next charge resistor and then calculate an RC time constant that will allow these stages to recharge in time. While this is an easy problem to understand a tool like SPICE is required to refine hand calculations.

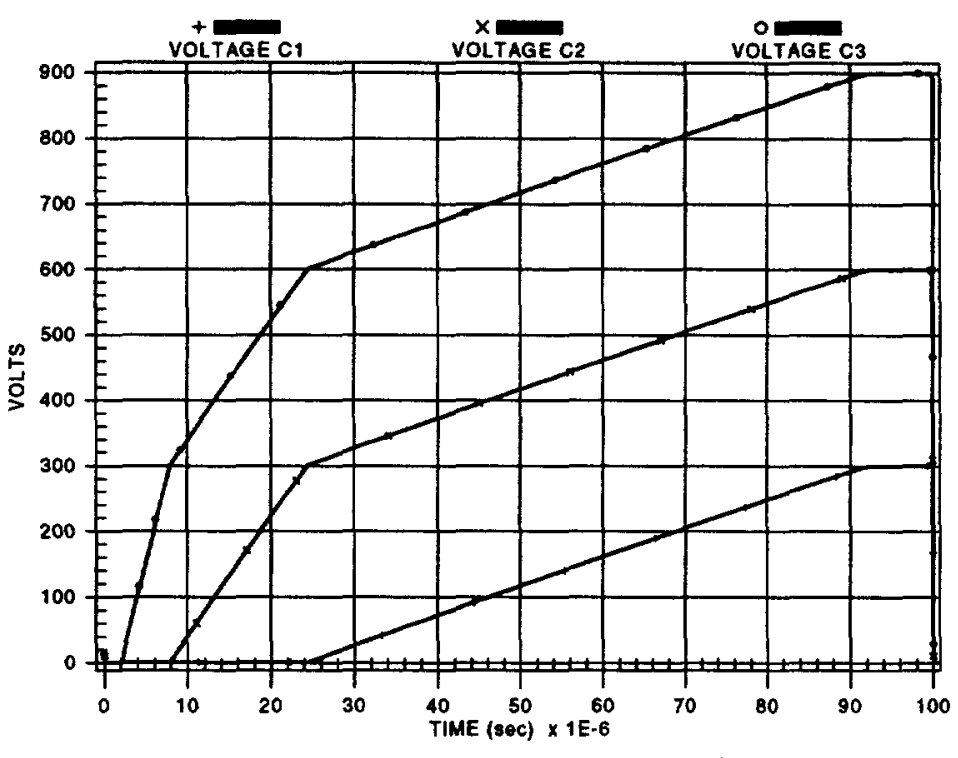

Figure 5. SPICE Simulation of Figure 2.

An unwanted side effect of introducing these additional charge resistors is an increase in the amount of current flowing in the zener diodes. This leads to higher than nominal voltage drops across the avalanche transistors. We have found through sad experience that if this voltage rises above $V_{c t o}$ the transistors re-trigger between pulses and 
soon fail. The nominal zener voltage of the parallel diodes must be reduced when operating at such high biases, in our $10 \mathrm{kHz}$ case we replace the $320 \mathrm{~V}$ units in the first three strings with $300 \mathrm{~V}$ devices and use $280 \mathrm{~V}$ diodes for the remainder of the string.

Our units draw 12 to 16 watts at $10 \mathrm{kHz}$, this waste heat must be removed from the compact enclosure or the temperature rise will effect the optical alignment of the Pockels cell. A small ( $40 \mathrm{~mm}$ square) 12vDC brushless motor rated at $7 \mathrm{cfm}$ is used to cool these drivers. The motors on these small fans are actually AC motors that are driven by a small integrated circuit oscillator integral to the fan. The electro-magnetic interference generated by the fast high voltage pulses was enough to interrupt the normal operation of the fan causing it to run slower. We found that we had to shield the motors from the EMI generated by the pulser.

\section{Pockels Cell Acoustic Resonance}

Extending Pockels cell repetition rates into the multi-kilohertz range has become a problem due to acoustic resonances. The high voltage pulses that drive the cell not only alter the polarization of light passing through the cell (the Pockels effect), but also cause the crystal to change shape (the piezoelectric effect). This mechanical stress acts as the "clapper" of a bell and the cell tends to "ring" for some period after it has been "struck" (see Figure 6) At low repetition frequencies this effect can be ignored because there is plenty of time for these acoustic oscillations to damp out. As we approach $10 \mathrm{kHz}$ however, some cells are still ringing when the next drive pulse arrives. In extreme cases we have observed continuous undamped oscillations. The length of the acoustic ringing varies greatly from cell to cell, even with cells of the same model number. We have found cells that are useable at $10 \mathrm{kHz}$, but currently each must be screened before it is put into service.

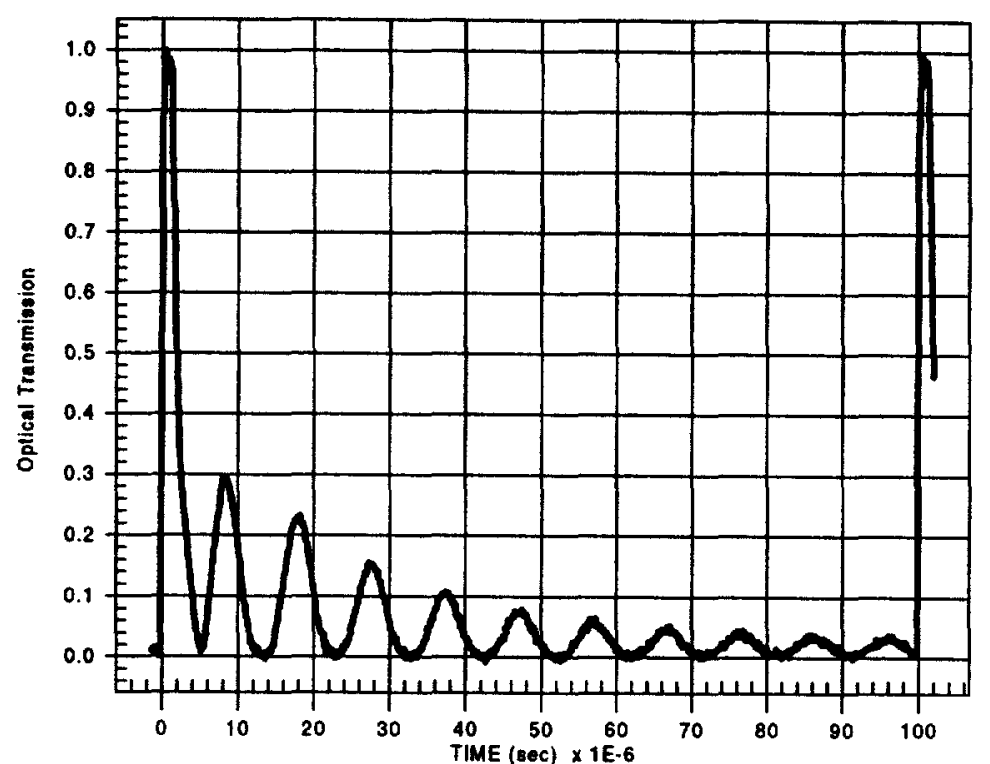

Figure 6. Pockels Cell Acoustic Ringing

So far we have evaluated twelve (12) Pockels cells, of four (4) model numbers, from three (3) manufacturers (referred to as Companies A, B and C). Laser light from an $800 \mathrm{~nm}$ CW laser diode was double passed through the cells and detected by a silicon photodiode. Each cell was tested at $1 \mathrm{kHz}$ to observe long term ringing and at $10 \mathrm{kHz}$ to observe any shot to shot effects. If a cell showed significant acoustic oscillations at $10 \mathrm{kHz}$, a "scan" at $100 \mathrm{~Hz}$ intervals was conducted to look for resonances.

The best performers were three Company A Cell 1 units that damped out to less than $1 \%$ of the normalized peak in less than $41 \mu \mathrm{s}$. Only one Cell 1 was found to be unusable (at $10 \mathrm{kHz}$ ) as that it was still ringing at about $3-4 \%$ of

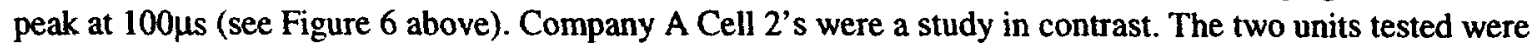
consecutive serial numbers (SN\#\#5/SN\#\#6), but showed completely different acoustic properties. Serial \#\#6 damped out in $65 \mu$ s and was acceptable for use at $10 \mathrm{kHz}$, but serial \#\#5 rang quite strongly and did not reach $1 \%$ until $175 \mu$ s.

The lone Company B cell tested rang very strongly. At $100 \mu$ s it was still swinging more than $10 \%$ of peak and oscillations could be seen out to $1 \mathrm{~ms}$. The mechanical " $\mathrm{Q}$ " of this cell was so high that at $9800 \mathrm{~Hz}$ we could obtain a continuous undamped ringing of the optical waveform. The Company $\mathrm{C}$ cell also showed strong acoustic oscillations. In fact, these oscillations built up to a peak of about $11 \%$ at $40 \mu$ s (due to a sub-harmonic) and did not decay below $1 \%$ for $270 \mu$ s. Continuous ringing could be obtained by driving the cell at $10.1 \mathrm{kHz}$. 
Overall test results are tabulated below:

\begin{tabular}{|l|l|c|c|}
\hline \multicolumn{1}{|c|}{ Manufacturer } & \multicolumn{1}{|c|}{$\begin{array}{c}\text { Model Number } \\
\text { Serial Number }\end{array}$} & $\begin{array}{c}\text { Damping Time } \\
(1 \%)\end{array}$ & $\begin{array}{c}\text { Acceptable } \\
\text { @ 10kHz }\end{array}$ \\
\hline Company A & Cell 1-1 & $69 \mu \mathrm{s}$ & Yes \\
\hline & Cell 1-2 & - & No \\
\hline & Cell 1-3 & $67 \mu \mathrm{s}$ & Yes \\
\hline & Cell 1-4 & $38 \mu \mathrm{s}$ & Yes \\
\hline & Cell 1-5 & $50 \mu \mathrm{s}$ & Yes \\
\hline & Cell 1-6 & $40 \mu \mathrm{s}$ & Yes \\
\hline & Cell 1-7 & $80 \mu \mathrm{s}$ & Yes \\
\hline & Cell 1-8 & $41 \mu \mathrm{s}$ & Yes \\
\hline & Cell 2-1 & $65 \mu \mathrm{s}$ & Yes \\
\hline & Cell 2-2 & $175 \mu \mathrm{s}$ & No \\
\hline & Cell 1 & - & No \\
\hline Company A & $-270 \mu \mathrm{s}$ & No \\
\hline Company C & Cell 1 & & \\
\hline
\end{tabular}

As a side issue we have calculated the velocity of sound in $\mathrm{KD} * \mathrm{P}$. By using the know dimensions of the crystals and taking the Fourier transform of the oscillations we computed the average velocity to be about $4400 \mathrm{~m} / \mathrm{s}$. This figure compares well with published data ${ }^{2}$ for $\mathrm{KCl}$ (a similar crystal) of $4140 \mathrm{~m} / \mathrm{s}$.

Acoustic resonance is a serious problem for Pockels cells when used in the multi-kilohertz regime. Admittedly our statistical universe is still small, but it appears that cells are available that will operate at these repetition rates (if they are prescreened). Working together with the manufacturers on modified cell mounting structures should lead to an improved yield of useable devices.

\section{Conclusion}

The authors have developed a versatile series of high performance Pockels cell drivers that are EMI quiet and clearly outperform any commercially available units in terms of rise time, compactness and high repetition rate operation with industry standard $10 \mathrm{~mm}$ aperture longitudinal cells.

\section{References}

1. E. S. Fulkerson, R. Booth, "Design of Reliable High Voltage Avalanche Transistor Pulsers", 21 st International Power Modulator Symposium, Costa Mesa, CA, June 1994

\footnotetext{
${ }^{2}$ CRC Handbook of Applied Engineering Science $2^{\text {nl }}$ Edition 1976 Table 7-44 Velocity of Sound in Bar-Shaped
} Solids Longitudinal Direction Potassium chloride ( $\mathrm{KCl}$, sylvite) $\mathrm{X}$-cut 


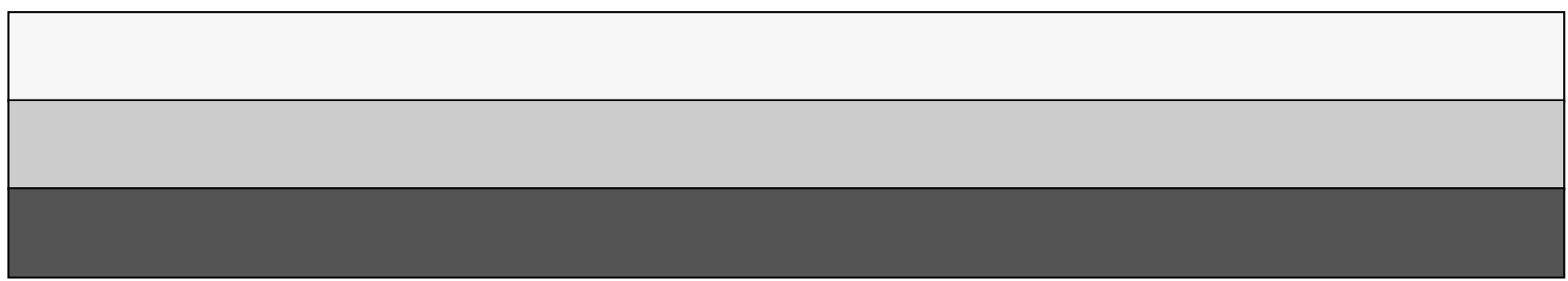

